\title{
Enseñar ciencias y, a la vez, promover la enculturación científica
}

En el transcurso de los últimos treinta años, la didáctica de las ciencias se ha consolidado como un campo de investigación y de sistematizaciones teóricas concernientes a las diversas facetas que caracterizan la enseñanza de las ciencias. Ese conjunto de conocimientos ha respaldado la planificación de cursos, cuyo propósito es hacer que los alumnos produzcan conocimientos significativos referidos no sólo al contenido de las asignaturas científicas, sino también al proceso de construcción de la ciencia misma, en especial a este último.

$\mathrm{Al}$ estudiar ese proceso, diversos investigadores han demostrado que la ciencia se puede entender como una cultura que tiene reglas, valores y lenguaje propios, por lo que su aprendizaje se debe tomar como un proceso de enculturación. A raíz de ello, uno de los principales papeles del profesor es introducir a sus alumnos en esa nueva cultura, ayudándolos a cruzar las fronteras entre la cultura cotidiana y la científica.

Introducir en la enseñanza las asignaturas de historia y filosofía de las ciencias siempre les pareció a los profesores, y también a los elaboradores de currículos, una de las actividades que facilitarían y ayudarían a los alumnos en ese proceso de transposición entre culturas. Sin embargo, la cuestión principal es precisamente cuál o cuáles aportes de este inmenso campo del conocimiento -historia y filosofía de las ciencias- serían importantes e incluso indispensables para la enseñanza de las Ciencias, y si tales aspectos serían los mismos para la enseñanza en la escuela básica que para la formación de los maestros.

Aunque partamos del principio de que no existe una fórmula "cerrada" para un concepto de ciencia, y de que la naturaleza del trabajo científico es un punto de debate en el que hay divergencias entre filósofos de la ciencia, así como también entre algunos autores que analizan a tales filósofos, podemos proponer algunos consensos que nos indican las contribuciones:

- La ciencia es una construcción histórica, humana, viva y, por ende, un conjunto de interpretaciones del mundo hechas por cada colectivo, desde su propia perspectiva.

- La ciencia es un conocimiento abierto, sujeto a cambios y reformulaciones.

- La construcción de este conocimiento se rige por paradigmas que influyen en la observación y la interpretación de un determinado fenómeno.

- El conocimiento científico no se construye específicamente, y uno de los objetivos de la ciencia es crear interacciones y relaciones entre las teorías. 
El problema estriba en convertir esas contribuciones consensuales relativas a las ciencias y al conocimiento científico en actividades de enseñanza. Si limitamos nuestra discusión solamente a la escuela básica, otros interrogantes deben complementar la cuestión principal para que se pueda alcanzar la enculturación científica en los discursos de los alumnos, por ser éste nuestro propósito. De nada sirve planificar clases amenas, ya que la idea es buscar indicadores que demuestran que los alumnos están ingresando a ese nuevo modo de pensar y de ver el mundo. Una de las preguntas que debemos contestar es ésta: ¿qué características deben tener las actividades de historia y filosofía de las ciencias en un curso de nivel medio, de tal manera que abarquen las contribuciones consensuadas antes señaladas?

La hipótesis que plantean varios investigadores en didáctica de las ciencias es que si las actividades (los textos elegidos) contienen por lo menos algunos de los puntos entre los valores internos y externos de las ciencias, éstas podrán fomentar en los alumnos discusiones sobre qué son las ciencias y cómo se produce ese conocimiento.

Como valores internos podemos citar los problemas enfocados, la importancia de los experimentos, el lenguaje científico y sus formas de argumentación, el formalismo matemático y la evolución de los conocimientos (crisis, controversias y cambios internos). Y como valores externos, las actividades deben valorizar adecuadamente el carácter colectivo del trabajo científico, las implicaciones sociales de la ciencia y la relación con los cambios ambientales (C/T/S/A).

Con la elección de textos originales de los científicos que relatan lo que hicieron y cómo solucionaron sus problemas, casi siempre se abarca una gran parte de los valores internos y externos de la relación antes citada; sin embargo, hace falta mucho trabajo para transformarlos en actividades que se han de desarrollar en clase. Primero, hay que traducirlos del idioma original -casi siempre el inglés- a la lengua materna, y luego, más difícil aún, se deben organizar preguntas que harán los profesores para suscitar la discusión con los alumnos y el debate relativo a los valores de las ciencias.

Ese debate, que involucra a los agentes sociales del aula, es una de las condiciones necesarias para promover la enculturación científica, pero sólo será efectivo en su plenitud si lo preceden una lectura individual del texto por todos los alumnos y una discusión, en pequeños grupos, entre los alumnos, para que puedan poner a prueba sus interpretaciones.

¿Qué aprenden los alumnos en ese tipo de clases? Esa es nuestra tarea. Buscamos indicadores en los discursos orales y en los trabajos escritos de los alumnos que nos demuestren si nuestras actividades los están ayudando a ingresar al universo de las ciencias.

Editorialista invitada 